\title{
Caregivers' practices, knowledge and beliefs of antibiotics in paediatric upper respiratorytract infections in Trinidad and Tobago: a cross-sectional study
} Neeta Parimi ${ }^{1,4}$, Lexley M Pinto Pereira*2 and P Prabhakar ${ }^{3}$

\author{
Address: ${ }^{1}$ Bishop Anstey High School, Port of Spain, Trinidad, ${ }^{2}$ Department of Paraclinical Sciences, Faculty of Medical Sciences, The University \\ of the West Indies, St Augustine, Trinidad, ${ }^{3}$ Caribbean Epidemiology Center (PAHO/ WHO), Port of Spain, Trinidad and ${ }^{4} \mathrm{RNA}$ Center, Case \\ Western Reserve University, Cleveland, OHIO, USA \\ Email: Neeta Parimi - neetaparimi@hotmail.com; Lexley M Pinto Pereira* - lpintopereira@fms.uwi.tt; P Prabhakar - Parimip1@hotmail.com \\ * Corresponding author
}

Published: 0I December 2004

BMC Family Practice 2004, 5:28 doi:10.1186/147/-2296-5-28

This article is available from: http://www.biomedcentral.com/I47/-2296/5/28

(C) 2004 Parimi et al; licensee BioMed Central Ltd.

This is an Open Access article distributed under the terms of the Creative Commons Attribution License (http://creativecommons.org/licenses/by/2.0), which permits unrestricted use, distribution, and reproduction in any medium, provided the original work is properly cited.
Received: 2I April 2004

Accepted: 01 December 2004

\begin{abstract}
Background: Antibiotic overuse and misuse for upper respiratory tract infections in children is widespread and fuelled by public attitudes and expectations. This study assessed knowledge, beliefs, and practices regarding antibiotic use for these paediatric infections among children's caregivers' in Trinidad and Tobago in the English speaking Caribbean.

Methods: In a cross-sectional observational study, by random survey children's adult caregivers gave a telephone interview from November 1998 to January 1999. On a pilot-tested evaluation instrument, respondents provided information about their knowledge and beliefs of antibiotics, and their use of these agents to treat recent episodes (< previous 30 days) of upper respiratory tract infections in children under their care. Caregivers were scored on an antibiotic knowledge test and divided based on their score. Differences between those with high and low scores were compared using the chi-square test.

Results: Of the 417 caregivers, $70 \%$ were female and between 18-40 years, $77 \%$ were educated to high school and beyond and $43 \%$ lived in urban areas. Two hundred and forty nine $(60 \%)$ respondents scored high $(\geq 12)$ on antibiotic knowledge and 149 (34\%) had used antibiotics in the preceding year. More caregivers with a high knowledge score had private health insurance $(33 \%),(p<0.02)$, high school education $(57 \%)(p<0.002)$, and had used antibiotics in the preceding year $(p<0.008)$ and within the last 30 days $(p<0.05)$. Caregivers with high scores were less likely to demand antibiotics $(p<0.05)$ or keep them at home $(p<0.001)$, but more likely to self-treat with antibiotics $(p<0.00 \mathrm{I})$. Caregivers administered antibiotics in 24I/288 (84\%) self-assessed severe episodes of infection $(p<0.00 \mathrm{I})$ and in 59/ $126(43 \%)$ cough and cold episodes without visiting a health clinic or private physician $(p<0.05)$.

Conclusions: In Trinidad and Tobago, caregivers scoring low on antibiotic knowledge have erroneous beliefs and use antibiotics inappropriately. Children in their care receive antibiotics for upper respiratory tract infections without visiting a health clinic or a physician. Educational interventions in the community on the consequences of inappropriate antibiotic use in children are recommended. Our findings emphasise the need to address information, training, legislation and education at all levels of the drug delivery system towards discouraging self-medication with antibiotics in children.
\end{abstract}




\section{Background}

Acute respiratory infections and diarrhoeal diseases are the leading causes of childhood mortality, resulting in $25-33 \%$ of all deaths in children in developing countries. Worldwide, antibiotics are the most commonly prescribed and abused drugs for upper respiratory tract infections (URTIs) $[1,2]$. In surveys on antibiotic use, about 20 $\%$ of prescriptions were inappropriate [3] and a high proportion of patients received antibiotics during clinic visits [4].

A significant force driving the occurrence and the spread of antibiotic resistance is the inappropriate use of antibiotics in primary and ambulatory care settings. Streptococcus pneumoniae, Hemophilus influenzae and Moraxella catarrhalis, the most common bacterial pathogens causing acute bacterial rhinosinusitis (ABRS) in children, in both the developed and developing countries, have already demonstrated resistance to the first line antibiotics [5-9]. The Sinus and Allergy Health Partnership (SAHP) guidelines for the treatment of ABRS observe antibiotics prescribed for ABRS are not only ineffective, but may contribute to the development of antibiotic-resistant bacterial infections [10] which is supported by the increasing resistance of Streptococcus pneumoniae and the increasing prevalence of strains resistant to the beta-lactams and cotrimoxazole. Unnecessary antibiotic use in viral respiratory illnesses in humans is a key factor influencing the emergence and spread of resistant pneumococci. Inappropriate antibiotic use may be consequent to misdiagnosis of the illness (viral and bacterial URTIs present with similar symptoms), patients' expectations, and their demands which induce physicians to prescribe antibiotics [11].

In the United States, a higher proportion of infections due to penicillin resistant pnuemococci among young children and whites have been attributed to an overuse of antibiotics $[12,13]$. Epidemiological studies demonstrate recent antibiotic use is strongly associated with carriage of resistant pneumococci in the community and the individual, and in patients with invasive pneumococcal disease, recent antibiotic use has been associated with increased risk of infection with a resistant strain [14].

Previous community-oriented studies suggest an irrational use of antibiotics, particularly in the developing and lesser-developed countries. Factors influencing antibiotic resistance are the higher incidence of infectious diseases in children, the lack of access to health care, costs and poor regulatory controls on the use of prescription drugs such as antibiotics, coupled with low antibiotic knowledge prompting increased self medication with these drugs [15-17]. As the first health-decision makers in deciding when to initiate antibiotic treatment and limit their unnecessary use, mothers and caregivers must have the appropriate knowledge to enable correct decisions. This first Caribbean study investigated the knowledge, beliefs and practices of children's caregivers in Trinidad and Tobago regarding antibiotic utilisation and explored these beliefs in self-administration of antibiotics in childhood URTIs. Gaining a better understanding of caregivers' management of childhood URTIs and factors that influence their use of antibiotics will allow appropriate educational interventions and reduce unnecessary antibiotic use in children.

\section{Methods \\ Setting}

Trinidad and Tobago, a twin island republic in the Caribbean located off the Venezuelan coast with a population of 1.3 million people is the second largest country in the English speaking Caribbean. About $74 \%$ of the country's population live in the urban areas and $60 \%$ of the population is aged between 15-64 years. The literacy rate in Trinidad and Tobago is $98 \%$ and at least $70 \%$ of the country's adult population has completed secondary (high) school to the pre-university level. Medical care in Trinidad and Tobago is publicly financed through three (3) regional health authorities (North West, South West and Eastern regions) in Trinidad, and one in Tobago. Secondary and tertiary care are provided at one general hospital in Port-of-Spain, one in San Fernando (1,245 beds), and at two county hospitals in Trinidad (111 beds), and at one hospital in Tobago ( 96 beds), besides institutions for specialised services. Primary health care is provided at 82 health centers in Trinidad and 19 in Tobago. The ratio of the population to a health center ranges from $<3000$ per center in Tobago to $>21,000$ per center in the north-west region. There are 33 private hospitals and approximately $45 \%$ of the population preferentially uses the private sector services. Private general practitioners are concentrated in the cities and larger towns and the estimated ratio of physician per population is 7.5 per 10,000 inhabitants [18].

\section{Design}

This prospective cross sectional observational study was conducted in Trinidad and Tobago from November 1998 to January 1999 in randomly selected subjects interviewed over the telephone. The study design and methods have been described previously [19]. Briefly, a sample size of 800 participants with a working telephone was calculated based on $80 \%$ power to detect a difference of at least $3 \%$ use of antibiotics giving an error of 0.05 . This being the first such telephone survey in the country, with no experience of the rejection rate, 1,600 telephone numbers were randomly obtained from a sampling frame of 167,272 telephone subscribers of The Telecommunication Services of Trinidad and Tobago, the only telephone service provider in the country. Of 824 respondents, 753 agreed to 
participate with a response rate of $91.4 \%$. At the outset of the study participants were questioned if they were caring for a child $\leq 12$ years and the term 'antibiotic' was explained in a simple sentence: "Antibiotics are drugs that are prescribed for the treatment of diseases caused by germs".

The pilot-tested questionnaire consisted of 42 items in three parts, designed to investigate knowledge, beliefs and practices of antibiotics [19]. The first part on the caregiver's demographic data included the employment status, health insurance and educational background. The second part inquired about caregivers' knowledge and beliefs. To determine antibiotic knowledge participants were asked to identify 4 antibiotics from a list of 8 commonly used drugs, and could attain a maximum score of 16. Caregivers' beliefs about antibiotics were determined using the following three questions: 1 . Do you think antibiotics can cure all infections? 2. Do you believe antibiotics are free from side-effects? 3. Do you think antibiotics are generally safe? From our earlier report and the pilot project of the current study respondents differentiated their understanding of 'side-effects' and 'safety'. The former was associated with unwanted disturbances from drug therapy on the quality of life and the latter was associated with life-threatening issues like organ toxicity and death. The third part of the questionnaire ascertained caregivers' practices of antibiotic use. They were asked about symptoms which children in their care had in the past 30 days, their assessment of the symptom severity, whether they sought medical assistance and if they administered any antibiotic to the child. Respondents were not asked to name the antibiotic. Information on suspected sideeffects or allergic reactions was excluded from the final questionnaire as these responses in the pilot study were uncertain and subject to memory recall.

\section{Analysis}

Four hundred and seventeen of the 753 respondents were adult caregivers with children in the family and their responses were analysed. An antibiotic knowledge score was created based on the caregivers' responses to eight common drugs, which included four antibiotics. A high Antibiotic Knowledge Score (AKS) was defined as that at or above the median score. Data were analysed using SPSS version 11.0 (Chicago), and associations were determined by the Chi square test for antibiotic knowledge and caregiver's education, beliefs and practices and recent and past antibiotic use for URTIs.

\section{Results}

The majority of respondents was female $(70 \%), \geq 31$ years, (72\%) and had completed high school (pre-university) education (77\%). There was a marginally high (57\%) representation from the rural area (Table 1), but residence showed no relation to the determinants of the study. The
Table I: Characteristics of children's caregivers in Trinidad and Tobago.

\begin{tabular}{|c|c|}
\hline Characteristics & $\begin{array}{l}\text { Caregivers } \\
\text { with children } \\
(n=4 I 7)\end{array}$ \\
\hline Number of people in the house (mean +/- SD) & $4.89+/-1.9$ \\
\hline Number of children (mean +/- SD) & $2.26+/-1.38$ \\
\hline \multicolumn{2}{|l|}{ Gender: } \\
\hline Males & $126(30) \%$ \\
\hline Females & $291(70 \%)^{*}$ \\
\hline \multicolumn{2}{|l|}{ Age group } \\
\hline $18-30 \mathrm{yrs}$ & $112(28 \%)$ \\
\hline $31-40$ yrs & 165 (42\%) \\
\hline$>41$ yrs & $129(30 \%)$ \\
\hline \multicolumn{2}{|l|}{ Residence } \\
\hline Rural & $235(57 \%)$ \\
\hline Urban & $176(43 \%)$ \\
\hline \multicolumn{2}{|l|}{ Ethnicity } \\
\hline African & $142(35 \%)$ \\
\hline Indian & $158(39 \%)$ \\
\hline Others & $110(29 \%)$ \\
\hline \multicolumn{2}{|l|}{ Education } \\
\hline Primary school & $96(23 \%)$ \\
\hline High school & $228(55 \%)^{*}$ \\
\hline College & $90(22 \%)$ \\
\hline \multicolumn{2}{|l|}{ Health Insurance } \\
\hline With Private Health insurance & $114(29 \%)$ \\
\hline Without Private Health insurance & 281 (7I\%)* \\
\hline Antibiotics used in previous year & $143(34 \%)$ \\
\hline Antibiotics used in last 30 days & 149 (35\%) \\
\hline
\end{tabular}

* Significant at $\mathrm{p}<0.05$

ratio of respondents with African and Indian heritage bore close similarity to the ethnic profile of the population in Trinidad and Tobago. Seventy one percent of caregivers with children did not have private health insurance. Comparable proportions of caregivers, 35\% and 34\% respectively reported using antibiotics recently ( $<30$ days) and in the past (within the last one year). The median antibiotic knowledge score was 12 and was determined by the correct identification of penicillin, tetracycline, 'Augmentin', and 'Bactrim' as antibiotics from a list of 8 common drugs. Two hundred and forty-nine (60\%) caregivers scored at or above the median score. The significant predictors of high antibiotic knowledge in caregivers were those who were employed, had private health insurance and, high school education. More caregivers with a high AKS had used antibiotics recently $(\mathrm{p}<0.037)$ and in the past $(\mathrm{p}<0.008)$ (Table 2$)$.

A majority of respondents had correct beliefs regarding whether 'antibiotics cure all infections' (54\% [227/417]) and 'antibiotics are free from side effects' (61\% [253/ 417]). Few (11\% [49/417]) respondents believed antibiotics are generally safe. and some caregivers (18\%-24\%) 
Table 2: Caregivers' Antibiotic Knowledge Score (AKS) and associated factors

\begin{tabular}{|c|c|c|c|}
\hline Factors & AKS $<12(n=168)(\%)$ & AKS $\geq I 2(n=249)(\%)$ & p VALUE \\
\hline \multicolumn{4}{|l|}{ Gender } \\
\hline Males & $51(30)$ & $51(30)$ & 0.96 \\
\hline Females & $117(70)$ & $117(70)$ & \\
\hline \multicolumn{4}{|l|}{ Residence } \\
\hline Rural & $75(46)$ & $101(4 I)$ & 0.29 \\
\hline Urban & $88(54)$ & 147 (59) & \\
\hline \multicolumn{4}{|l|}{ Health Insurance } \\
\hline Has insurance & $35(22)$ & $79(33)$ & $0.02^{*}$ \\
\hline Does not have & $122(78)$ & $159(67)$ & \\
\hline \multicolumn{4}{|l|}{ Age Groups } \\
\hline $18-30 \mathrm{yrs}$ & $55(34)$ & $57(23)$ & 0.07 \\
\hline $31-40$ yrs & $60(37)$ & $105(43)$ & \\
\hline$>41$ yrs & $47(29)$ & $82(34)$ & \\
\hline \multicolumn{4}{|l|}{ Ethnicity } \\
\hline African & $57(35)$ & $85(35)$ & 0.70 \\
\hline Asian & $67(4 I)$ & $91(37)$ & \\
\hline Others & $41(24)$ & $69(28)$ & \\
\hline \multicolumn{4}{|l|}{ Education } \\
\hline Primary & $53(37)$ & $43(17)$ & $0.002^{*}$ \\
\hline High School & $87(52)$ & $14 \mid(57)$ & \\
\hline Tertiary Education & $28(18)$ & $62(26)$ & \\
\hline \multicolumn{4}{|l|}{ Employment } \\
\hline Employed & $69(43)$ & $130(54)$ & 0.09 \\
\hline Self Employed & $28(18)$ & $40(17)$ & \\
\hline Housewife/retired/unemployed & $62(39)$ & $71(29)$ & \\
\hline \multicolumn{4}{|l|}{ Recent and past antibiotic use } \\
\hline Used in the last 12 months & $45(27)$ & $98(40)$ & $0.008 *$ \\
\hline Not used in the last 12 months & $118(70)$ & $150(60)$ & \\
\hline Used in the last 30 days & $50(30)$ & $99(40)$ & $0.037^{*}$ \\
\hline Not used in the last 30 days & $122(73)$ & $150(60)$ & \\
\hline
\end{tabular}

Significant at $(p<0.05)$

remained non-responsive to all questions. The AKS of caregivers did not influence their beliefs (Table 3). Eighty six caregivers $(22 \%)$ admitted to demanding antibiotics from a doctor. More caregivers $(28 \%)$ with a low AKS demanded antibiotic prescriptions $(\mathrm{p}<0.05)$ and kept these drugs at home $(33 \%)(p<0.001)$, to treat illnesses. Self-initiation of treatment for URTIs with antibiotics was more frequent $(\mathrm{p}<0.05)$ among caregivers who had a high AKS. Caregiver's knowledge scores were not associated with the use of antibiotics given by relatives and / or friends or with compliance with the course whether recommended by the pharmacist or the doctor. (Table 3).

Caregivers reported as many as 450 episodes of URTIs in children within the previous 30 days (1.07 episodes per family) and 149 (35\%) caregivers self-administered antibiotics in $64 \%(288 / 450)$ of these episodes. Cough and cold was the most frequently reported URTI symptom $(48 \%, 214 / 450)$ followed by fever $(28 \%, 128 / 450)$ and sore throat $(24 \%, 108 / 450)$. Caregivers were more likely to give children antibiotics when they perceived URTIs to be severe $[241 / 288(84 \%)](\mathrm{p}<0.001)$, and administered these drugs for the common cold $[112 / 136,(82 \%)]$ fever [75/87 (83\%)] and sore throat [54/65 (86\%)] (Table 4). In $16 \%$ of episodes which caregivers deemed to be of mild severity, they self-administered antibiotics. Children received antibiotics without visiting a health clinic or a private physician for 126 (44\%) URTI episodes, and more frequently for the common cold 59 (43.7\%) compared with fever and sore throat $(\mathrm{p}<0.05)$.

\section{Discussion}

This cross sectional study in Trinidad and Tobago determined the antibiotic knowledge of children's caregivers and the influence of this knowledge on their beliefs and use of these agents for URTIs in children under their care. We found high school education and higher socio-economic status (income permitted private health insurance) was significantly associated with higher knowledge scores. 
Table 3: Antibiotic beliefs and practices of Caregivers in Trinidad

\begin{tabular}{|c|c|c|c|}
\hline FACTORS & AKS $<12(\%)$ & AKS $\geq 12$ (\%) & $P$ value \\
\hline \multicolumn{4}{|l|}{$\begin{array}{l}\text { I. Antibiotic Beliefs: } \\
\text { a. Cure all infections }\end{array}$} \\
\hline Agree & $48(37)$ & $63(30)$ & 0.17 \\
\hline Disagree & $81(63)$ & $146(70)$ & \\
\hline \multicolumn{4}{|l|}{ b. Free from side -effects } \\
\hline Agree & $21(18)$ & $44(21)$ & 0.30 \\
\hline Disagree & $99(82)$ & $153(79)$ & \\
\hline \multicolumn{4}{|l|}{ c. Generally safe } \\
\hline Agree & $21(17)$ & $28(13)$ & 0.40 \\
\hline Disagree & $105(83)$ & $183(87)$ & \\
\hline \multicolumn{4}{|l|}{ 2. Antibiotic Practices } \\
\hline \multicolumn{4}{|c|}{ Demands from doctor for URTI in children } \\
\hline Yes & $4 \mid(28)$ & $45(19)$ & $0.05^{*}$ \\
\hline No & $106(72)$ & $188(81)$ & \\
\hline \multicolumn{4}{|l|}{ Keeps at home } \\
\hline Yes & $53(33)$ & $45(19)$ & $0.001 * *$ \\
\hline No & $107(67)$ & $195(91)$ & \\
\hline \multicolumn{4}{|l|}{ Self treatment } \\
\hline Yes & $33(12)$ & $69(32)$ & \\
\hline No & $154(88)$ & $150(68)$ & $0.001 * *$ \\
\hline \multicolumn{4}{|l|}{ Given by friends and relatives } \\
\hline Yes & $16(10)$ & $25(\mathrm{II})$ & \\
\hline No & $142(90)$ & $213(89)$ & 0.9 \\
\hline \multicolumn{4}{|l|}{ Compliance } \\
\hline Yes & $89(63)$ & $152(7 \mid)$ & \\
\hline No & $52(37)$ & $63(29)$ & 0.13 \\
\hline
\end{tabular}

*Significant at $\mathrm{p}<0.05$, ** Significant at $\mathrm{p}<0.001$

Table 4: Antibiotic administration by caregivers for severe URTIs $(n=288)$ and visits to health provider

\begin{tabular}{lllllll}
\hline URTI Episodes & \multicolumn{2}{l}{ Assessed severe by caregiver (\%) } & & \multicolumn{2}{c}{ Visited a health clinic/private physician (\%) } \\
& Yes & No & Total & Yes & No & Total \\
Cough and Cold & II $(82)$ & $24(18)$ & 136 & $77(57)$ & $59(43) *$ & 136 \\
Fever & $75(83)$ & $12(17)$ & 87 & $55(63)$ & $32(37)$ & 87 \\
Sore throat & $54(86)$ & $11(14)$ & 65 & $30(46)$ & $35(54)$ & 65 \\
Total & $24 I(84)^{* *}$ & $47(16)$ & 288 & $162(56)$ & $126(44)$ & 288 \\
\hline
\end{tabular}

* Significant at $p<0.05$

** Significant at $p<0.001$

Similar associations between knowledge and antibiotic use were reported in a study in the Indian state of Kerala [20]. In the present study more caregivers who scored high on antibiotic knowledge, had used antibiotics (recently and in the past) compared with those who attained a low knowledge score.

A significant proportion of caregivers in the present study had misconceptions that could contribute to the inappropriate use of antibiotics. Equal proportions of caregivers with high and low knowledge scores believed that antibiotics cure all infections and are free from sideeffects. Even though URTIs are generally of viral aetiology $[21,22]$, these mistaken beliefs may have steered antibiotic abuse from self treatment or over the counter demands at the pharmacy which are fostered from easy availability of these drugs at community pharmacies in Trinidad and Tobago [19]. In a survey from the United States, $48 \%$ of paediatricians reported parents do pressure them to prescribe antibiotics [23], and 78\% of the sample believed educating parents on appropriate indications for antibiotic use was the single most important factor to pro- 
mote suitable prescribing, suggesting effective communication between physicians and parents may reduce inappropriate antibiotic prescribing.

Practices such as demanding a prescription for antibiotics from a physician, and keeping antibiotics at home (hoarding) were higher in caregivers with a low AKS. In Israel Shlomo et al [24] found lower education was a predictor of parents' expectations to receive antibiotics for URTIs and in Trinidad, Mohan et al reported that general practitioners attributed antibiotic over-prescribing in general practice to parents' demands [25]. A proclivity to demand antibiotics was associated with decreased knowledge and in children from insured families higher rates of antibiotic use were associated with low antibiotic knowledge and a tendency to demand antibiotics [26]. In Hong Kong educated respondents and working guardians had higher knowledge scores, and those who knew the viral aetiology of URTIs were less likely to demand antibiotics [27]. In the present study, the rate of self-treatment with antibiotics by caregivers, was higher in those who had a high AKS (32\%vs12\%). This may be consequent to caregivers needing to report for work following quicker recovery of children whom they care for. Braun and Fowles found a correlation between the expectation to get antibiotic treatment and parents' occupation and parents who worked full time had higher expectations to get antibiotic treatment, assuming perhaps that antibiotics shorten disease duration and allow an earlier return to work [28]. In Trinidad and Tobago at least $25 \%$ of the population demand a prescription for antibiotics from a doctor and 21\% keep antibiotics in the house for emergency purposes [19]. Educational campaigns for the public can correct the widespread misconceptions on antibiotic use and storage.

Earlier in describing the prescribing practices of Caribbean physicians we reported that respiratory tract infection was the most frequent reason for antibiotic prescriptions by physicians in the English and Dutch speaking Caribbean [29]. The influence of caregivers' (parents and relatives) knowledge on antibiotic use in children with URTIs has not been studied in any Caribbean region. Proportionately more children received antibiotics from caregivers for severe episodes of cold and cough, than for sore-throat and fever. Even for what they considered mild episodes (16\%) of URTIs, caregivers administered antibiotics which as is current practice, probably obtained from community pharmacies on request [19]. In Malta parents gave antibiotics to their children without a prescription particularly for sore throat and the community pharmacy made the drugs available [30]. Caregivers in our study treated $44 \%$ of URTIs in children with antibiotics without consulting a physician or attending a health facility. We did not ascertain if the child suffered any unwanted effects of the drug, which information may have been important to discuss the consequences of freely giving antibiotics to children. We believe caregivers with health insurance, education beyond the primary level and a high AKS had obtained antibiotics informally at community pharmacies and those with a low knowledge score initiated medication with antibiotics from the home storage or given them by relatives and friends. A call for strict vigilance and enforced controls regarding 'over-the-counter' availability of antibiotics without a physician's prescription, despite being controlled drugs in Trinidad and Tobago, has been made in an earlier report [19].

Inappropriate antibiotic use is a common practice in the out patient setting in a clinic, or a physician's office [31,32], and has been attributed to the combination of time pressures of outpatient practice, diagnostic uncertainty, and physicians' misconceptions of patient expectations [33]. The cost and time spent for a visit to the health center or a physician's office and a genuine concern about the children's health could have pushed caregivers in Trinidad and Tobago to purchase antibiotics without a prescription which is a widespread practice here, and initiate treatment for common childhood respiratory tract illnesses. In Africa, Asia and Latin America antibiotics are obtained from pharmacies, hospitals and even from untrained vendors at the market place [21,34-36]. In Bavi, Vietnamese children were treated with antibiotics frequently by caregivers without physician consultation, resulting in a high prevalence of multi drug-resistant strains (MDR) among respiratory pathogens [37]. Contributing to the existence of the reservoir of MDR genes among bacterial pathogens undermines the effectiveness and success of antibiotic therapy in childhood respiratory tract infections in low-income countries.

\section{Conclusions}

Inappropriate antibiotic use for paediatric URTIs in Trinidad and Tobago may have been facilitated by low knowledge, erroneous beliefs and easy availability of these drugs without the required prescription, at a retail pharmacy. A combination of education and communication to combat patients' expectations for treatment, and the physicians' appropriate prescription for antibiotics can halt inappropriate antibiotic use in children. Using narrow-spectrum antibiotics, promoting dialogue with caregivers to discuss symptom relief and antibiotic resistance, and encouraging active management of the child's illness with follow-up calls is recommended. Pharmacists have a serious responsibility not to dispense these agents without prescriptions and to discourage patients from obtaining these drugs for self-treatment. Widespread educational campaigns targeting the general public in Trinidad and Tobago, particularly parents and caregivers of young children should 
focus on the difference in bacterial and viral infections and the futility of treating viral infections with antibiotics. A multidisciplinary approach to rational antibiotic use, dispensing these drugs as 'prescription only medicine' and educating the public can halt inappropriate use and contain resistance.

\section{List of abbreviations \\ ABRS = Acute Bacterial Rhinosinusitis \\ AKS = Antibiotic Knowledge Score \\ SAHR $=$ Sinus and Allergy Health Partnership \\ URTI = Upper Respiratory Tract Infection}

\section{Competing interests}

The author(s) declare that they have no competing interests.

\section{Authors'contributions}

PP conceptualised the study and drafted the protocol, NP did data collection, and contributed to the draft manuscript, LMPP prepared the final manuscript. All authors contributed to the statistical analysis and the literature search.

\section{Acknowledgements}

Dr.Elaine Borawski and Dr C C Whalen, Case Western Reserve University critically reviewed the manuscript and made helpful comments. The Principal and Teachers of Bishop Anstey High School, Trinidad supported the study.

\section{References}

I. World Health Organization: The World Drug Situation. Geneva 1988.

2. World Health Organization: The World Health Report. Geneva 1996.

3. Trostle J: Inappropriate distribution of medicines by professionals in developing countries. Social Science and Medicine 1996, 42: I I I7- II 20

4. Hogerzeil HV, Bimo, Ross-Degnan D, Laing RO, Ofori-Adjei D, Santoso B, Azad Chowdhury AK, Das AM, Kafle KK, Mabadeje AF: Field tests for rational drug use in twelve developing countries. Lancet 1993, 342:|408-|4|0.

5. Wolff MJ: Use and misuse of antibiotics in Latin America. Clin Infect Dis 1993, I 7(Suppl 2):S346-35I.

6. Acar JF: Resistance patterns of Haemophilus influenzae. J Chemother 1999, I I(SuppI I):44-50.

7. Mathai D, Lewis MT, Kugler KC, Pfaller MA, Jones RN: Antibacterial activity of $4 I$ antimicrobials tested against over 2773 bacterial isolates from hospitalized patients with pneumonia: I - results from the SENTRY Antimicrobial Surveillance Program (North America, 1998). Diagn Microbiol Infect Dis 200I, 39:105-II6.

8. Jones RN, Croco MA, Kugler KC, Pfaller MA, Beach ML: Respiratory tract pathogens isolated from patients hospitalized with suspected pneumonia: frequency of occurrence and antimicrobial susceptibility patterns from the SENTRY Antimicrobial Surveillance Program (United States and Canada, 1997. Diagn Microbiol Infect Dis 2000, 37: I I5-125.

9. Gruneberg RN, Felmingham D: Results of the Alexander Project: a continuing, multicenter study of the antimicrobial susceptibility of community-acquired lower respiratory tract bacterial pathogens. Diagn Microbiol Infect Dis 1996, 25:169-I81.
10. Sinus and Allergy Health Partnership: Antimicrobial treatment guidelines for acute bacterial rhinosinusitis. Otolaryngol Head Neck Surg 2000, I 23(Suppl): I-32.

II. Vinson DC, Lutz LJ: The effect of parental expectations on treatment of children with a cough: Report from ASPN. J Fam Pract 1993, 37:23-27.

12. Whitney CG, Farley MM, Hadler J, Harrison LH, Lexau C, Reingold A, Lefkowitz L, Cieslak PR, Cetron M, Zell ER, Jorgensen JH, Schuchat A, Active Bacterial Core Surveillance Program of the Emerging Infections Program Network: Increasing Prevalence of multi-drug resistant Streptococcus pneumoniae in the United States. New Engl J Med 2000, 343:1917-1924.

13. Melnick SL, Sprafka JM, Laitinen DL, Bostick RM, Flack JM, Burke GL: Antibiotic Use in urban whites and blacks: Minnesota Heart Survey. Ann Pharmacother 1992, 26: I 292-I 295.

14. Guillemot D, Carbon C, Balkau B, Geslin P, Lecoeur H, VauzelleKervroedan F, Bouvenot G, Eschwege E: Low dosage and long term treatment duration of beta-lactam: risk factors for carriage of penicillin- resistant Streptococcus pnuemoniae. JAMA 1998, 279:365-370.

15. Hart CA, Kaiuki S: Antimicrobial resistance in developing countries. BMJ 1998, 31 7:647-650.

16. Kunin CM: Resistance to antimicrobial drugs: a worldwide calamity. Ann Intern Med 1993, I I 8:557-56I.

17. Richman PB, Garra G, Eskin N, Nashed AH, Cody R: Oral antibiotic use without consulting physician: a survey of ED patients. $A M$ J Emerg Med 200I, 19:57-60.

18. Promoting Health in the Americas [http://www.paho.org/Eng lish/SHA/prfltrt.htm]

19. Parimi N, Pinto Pereira LM, Prabhakar P: The general public's perceptions and use of antimicrobials in Trinidad and Tobago. Rev Panam Salud Publica 2002, I 2: I I- I8.

20. Saradamma RD, Higgnbotham N, Nlchter M: Social factors influencing the acquisition of antibiotics without prescription in Kerala State, South India. Soc Sci Med 2000, 50:89I-903.

21. Obaseiki-Ebor EE, Akerele JO, Ebea PO: A survey of antibiotic outpatient prescribing and antibiotic self- medication. J Antimicrob Chemother 1987, 20:759-763.

22. Sturm AW, van der Pol R, Smits AJ, van Hellemondt FM, Mouton SW, Jamil B, Minai AM, Sampers GH: Over -the -counter availability of antimicrobial agents, self-medication and patterns of resistance in Karachi, Pakistan. J Antimicob Chemother 1997, 39:543-547.

23. Bauchner H, Pelton S, Klein J: Parents, physicians, and antibiotic use. Pediatrics 1999, 103:395-401.

24. Shlomo V, Adi R, Eliezer K: The knowledge and expectations of parents about the role of antibiotic treatment in upper respiratory tract infection - a survey among parents attending the primary physician with their sick child. BMC Fam Pract 2003, 4:20.

25. Mohan S, Dharamraj K, Dindial R, Mathur D, Parmasad V, Ramdhanie J, Matthew J, Pinto Pereira LM: Physician behaviour for antimicrobial prescribing for paediatric upper respiratory tract infections: a survey in general practice in Trinidad, West Indies. Annals of Clinical Microbiology and Antimicrobials 2004, 3: I I.

26. Kuzujanakis M, Kleinman K, Rifas-Shiman S, Finkelstein JA: Correlates of parental antibiotic knowledge, demand, and reported use. Ambul Pediatr 2003, 3:203-210.

27. Chan CS: What do patients expect from consultations for upper respiratory tract infections? Fam Pract 1996, 1 3:229-235.

28. Braun BL, Fowles JB: Characteristics and experiences of parents and adults who want antibiotics for cold symptoms. Arch Fam Med 2000, 9:589-595.

29. Pinto Pereira LM, Prabhakar P: A survey on antibiotic prescribing practices of physicians in the Caribbean. Caribbean Med J 1999, 6 I (Suppl I): 19-20.

30. Borg MA, Scicluna EA: Over-the-counter acquisition of antibiotics in the Maltese general population. Int J Antimicrob Agents 2002, 20:253-257.

31. Watson RL, Dowell SF, Jayaraman M, Keyserling $H$, Kolczak M, Schwartz B: Antimicrobial use for pediatric upper respiratory infections: reported practice, actual practice and parent beliefs. Pediatrics 1999, 104:|25|-1257.

32. Schwartz RH, Freij BJ, Ziai M, Sheridan MJ: Antimicrobial prescribing for acute purulent rhinitis $n$ children: a survey of pediatricians an family practitioners. Pediatr Infect Dis J 1997, I 6: I85-190. 
33. Avorn J, Solomon D: Cultural and economic factors that (mis)shape antibiotic use: the non-pharmacological basis of therapeutics. Ann Intern Med 2000, 133:128-135.

34. Dua $\mathrm{V}$, Kunin CM, White LV: The use of antimicrobial drugs in Nagpur, India. A window of medical care in a developing county. Soc Sci Med 1994, 38: 17-24.

35. Lansang MA, Lucas-Aquino R, Tupasi TE, Mina VS, Salazar LS, Juban N Limjoco TT, Nisperos LE, Kunin CM: Purchase of antibiotics without prescription in Manila, the Philippines. Inappropriate choices and doses. J Clin Epidemiol 1990, 43:6I-67.

36. Wolf MJ: Use and misuse of antibiotics in Latin America. Clin Infect Dis 1993, I 7(SuppI I):346-35I.

37. Larsson M, Kronvall G, Chuc NT, Karlsson I, Lager F, Hanh HD, Tomson G, Falkenberg : Antibiotic medication and bacterial resistance to antibiotics: a survey of children in a Vietnamese community. Trop Med Int Health 2000, 5:71 I-72I.

\section{Pre-publication history}

The pre-publication history for this paper can be accessed here:

http://www.biomedcentral.com/1471-2296/5/28/prepub

Publish with Biomed Central and every scientist can read your work free of charge

"BioMed Central will be the most significant development for disseminating the results of biomedical research in our lifetime. "

Sir Paul Nurse, Cancer Research UK

Your research papers will be:

- available free of charge to the entire biomedical community

- peer reviewed and published immediately upon acceptance

- cited in PubMed and archived on PubMed Central

- yours - you keep the copyright

Submit your manuscript here:

http://www.biomedcentral.com/info/publishing_adv.asp 